International Journal of Technology and Design Education 8, 203-220, 1998.

(C) 1998 Kluwer Academic Publishers. Printed in the Netherlands.

\title{
Problem Solving in Real-Life Contexts: An Alternative for Design in Technology Education ${ }^{1}$
}

\author{
ANN MARIE HILL \\ Queen's University, Kingston, Ontario
}

ABSTRACT: This article focuses on one way to study technology, through technological problem solving situated in real-life contexts. In problem solving for real-life contexts, design processes are seen as creative, dynamic and iterative processes that engage exploration; join conceptual and procedural knowledge-both thought and action; and can encourage considerations to technology, human and environmental interactions. This approach is a demarcation from what is typically found in schools; design, make and appraise cycles based on closed design briefs that are teacher assigned and unrelated to the students' world. An interpretation of technology education as problem solving for real-life contexts using design processes as tools for creation and exploration offers an alternative approach to design in technology education. Alternative curriculum and instruction then emerge. Elementary and secondary school programs in technology education and teacher education can all be seen through this kind of design lens. Episodes from case studies are reported with the intent to briefly describe technology education programs in elementary and secondary schools that interpret technology education in this way. Educational implications of this approach are offered.

Keywords: community, creativity, design processes, exploration, invention, problem solving, real-life contexts, technology education

\section{INTRODUCTION}

In this article I shall focus on one way to study technology, through technological problem solving situated in real-life contexts. Design processes guide problem solving in technology education as the inquiry method guides science education. In problem solving for real-life contexts, design processes are seen as creative, dynamic and iterative processes that engage exploration; join conceptual and procedural knowledge-both thought and action; and can encourage considerations to technology, human and environmental interactions. This approach is a demarcation from what is typically found in schools; design, make and appraise cycles based on closed design briefs that are teacher assigned and unrelated to the students' world.

This contrast raises interesting questions of 'fit' of such narrowly defined design processes, frequently depicted as prescribed, systematic and linear, in technological problem solving which is open-ended, dynamic and creative. An interpretation of technology education as open-ended problem solving for real-life contexts using design processes as tools for creation and exploration offers an alternative approach to design in technology education. Alternative curriculum and instruction then emerge. Elementary and secondary school programs in technology education and teacher 
education (Hill, 1997; Hill \& Hopkins, 1997) can all be seen through this kind of design lens.

Throughout this paper, I refer to 'technology' as the use of materials, energy, skills and knowledge to create artefacts, systems, processes, or even new knowledge to meet human needs in a context of human and environmental considerations through open-ended problem solving. 'Technology education' is defined as the study of technology in elementary and secondary schools where students are provided the opportunity to use a variety of materials and processes to solve real-life technological problems; to develop technological skills and concepts and the ability to use tools (including computers); to acquire an understanding of various technological systems and processes; to evaluate the impact of technology on people and the environment; and to develop the confidence to be risk takers in technological problem solving.

\section{OBJECTIVES}

I begin this article with a brief discussion of design process models. To substantiate the idea of design processes as creative and dynamic that engage exploration, I link the idea of creativity to technological problem solving and design processes. I then extend this dialogue to examine what openended technological problem solving situated in real-life contexts offers technology education. The reporting of episodes from case studies forms the remainder of the paper. The intent is to briefly describe technology education programs in elementary and secondary schools that interpret technology education as open-ended problem solving using design processes for real-life contexts. I conclude by considering some educational implications of this approach.

\section{THEORETICAL FRAMEWORK}

\section{Design processes}

There are many design process models found in the literature. The models portray processes of low to high complexity (See Beakley, 1975; Cross, 1983; Dunn \& Larson, 1990; Eggleston, 1992; Kimbell, 1986; Norman et al., 1990; Tickle, 1990; Walker \& Cross, 1983; Williams, 1990 for a variety of design processes). Regardless of the degree of complexity, all models describe a common thread: a process that moves from the inception of an idea, to the reflection stage in order to verify if the developed model, prototype or system functions as intended. Debate about details of complexity or selection of a 'best' design process is not the focus of this discussion. The salient point is that when we move from theory into actual practice, how one moves through design processes is a unique and individual expe- 
rience (Dunn \& Larson, 1990; Raizen et al., 1995). Therefore, it is questionable to present it to students as a linear, simple process.

Self-study research (See Friesen, 1997; Taylor, 1991 for self-study research) in teaching pre-service teachers (Hill, 1997), and research that examines how elementary school children, and high school students (Hill \& Smith, 1996, 1997) work through technological problem solving and design processes indicates that it is important to incorporate problem solving and design processes as part of the actual technology education curriculum. This inclusion clarifies to students expectations, the idea that there are many different design process models that can be used to solve technological problems, and that these processes are not linear, systematic or predictable with one right answer. Another finding from these studies is that when the students were allowed to move through technological problem solving using design as exploration, creativity was fostered and this enriched student learning. As one grade 11 student said, 'It's natural creativity and you get to put your own expression into what you do as well as learn other things that interest you' (GY Group Interview, JE, 1995.11.17). This approach also encourages learning process, skills and knowledge simultaneously and in context, and this encourages student success in technological problem solving (Jones \& Carr, 1994).

Jones (1997a) elaborates this point:

The teaching of the design cycle without an equal emphasis on knowledge and reflection causes difficulties for the students. McCormick et al. (1994) indicate that the conceptual demands of a task are more influential than the procedural, and they stress the importance of developing global aspects before local skills. Pupils have commented that they were often confused by the conceptual demand of a project and lack of explicit process teaching. Teachers need to make the process, their rationale and criteria explicit to pupils. (p. 92)

\section{Design processes as creative process}

Creativity is usually apparent in all stages of design processes, but is particularly prominent in the early stages. Wallas $(1926,1973)$ identifies and describes four stages, which he calls 'stages of control', in his dialogue about the creative process; preparation, incubation, illumination and verification. Lawson (1990) and Norman et al. (1990) use these same terms but add a different and additional beginning stage, first insight. They describe first insight as recognising that a problem exists and deciding to tackle it, preparation as an attempt to understand the problem and to produce solutions, incubation as periods of relaxation allowing subconscious thought, illumination as sudden emergence of the idea (the 'act of insight' or 'creative leap'), and verification as conscious development and testing of the idea into a workable solution (p. 19). But how are we to interpret creativity in the light of technology education? We are comfortable to think of creativity linked to the arts, but its association with technology is less usual. Two points clarify this association. First, the technological design process shares features of what has been explored in research on the creative process 
and second, research on types of creativity expands our understanding of creative acts.

Different types of creativity are described by Taylor (1975) in his dialogue about 'transactional disposition of creativity'. He identifies five types of creativity; productive or technical, inventive, expressive, innovative and emergentive. Productive or technical creativity is "characterized by proficiency in creating products and is essential at the technical production level. The emphasis is on skill at the expense of expressive spontaneity. It is essentially concerned with novelty, although it does involve the achievement of a new level of proficiency by the individual' (p. 306). Inventive creativity is 'characterized by a display of ingenuity with materials. It involves insight into unusual combinatory relationships between things previously separated, for the purpose of solving old problems in new ways. Creativity at this level does not result in new basic ideas, but in new usages of old parts and new ways of seeing old things' (p. 306). In describing expressive creativity, Taylor says that it 'is the most fundamental form involving independent expression skills. Originality and quality of product are unimportant ... The important characteristics are spontaneity and freedom which form the foundation upon which more creative talents develop' (p. 306). For innovative creativity, 'the basic assumptions and principles are understood so that modification through alternative approaches is possible. Innovative creativity is dependent upon the ability to penetrate and understand basic foundational principles' (p. 307). Emergentive creativity is seen as the most complex form of creativity 'involving the most abstract ideational principles or assumptions underlying a body of art or science... What is involved is an ability to absorb experiences which are commonly provided and from this produce something that is quite different' (p. 307). Those involved in technological problem solving using design processes will recognise some of the above types of creativity as activities in which they or their students engage.

While research on creativity began in the 1960s, its importance even today is evidenced by ongoing research. Runco and Albert (1990) have reviewed recent research on creativity. In their edited collection Milgram (1990) links creativity to recent research on learning styles, a very recent concept, and argues, 'Is creativity an idea whose time has come and gone? I do not think so. I believe that it is an idea whose time is still coming, an idea that is still in the process of becoming' (p. 215). This position is elaborated:

Creativity is important because it enhances the quality of solutions to life's problems. Creative thinking results in original solutions to problems that continually arise in the personal and vocational spheres. Business, industry, and military leaders have made strenuous efforts to identify and to enhance innovative thinking. Creativity, however, is not reserved to the high and mighty. Creative thinking can enhance the quality of our everyday lives. Students of all ages place high value on creative thinking on the part of their teachers. . . Creativity is important because it predicts life achievement better than more conventional and widely used predictors. (pp. 215-216) 
I now return to my earlier point that when students are allowed to move through technological problem solving using design as exploration, creativity is fostered and learning is enhanced. In problem solving for real-life contexts, design processes are seen as creative and dynamic processes that engage exploration. Through exploration, confidence in the freedom to explore and take risks is fostered. This confidence becomes critical when we understand that in creation and invention, there are always states of order and disorder. Waetjen (1995) talks about this unpredictable nature in the technological design process:

Technological innovation is an exceedingly complex system where there is, presumably, disorder even within the order of the technological process. Discovering that order with disorder involves cognition and application, knowledge and control, mind and matter, purpose and tools, will be of increasing importance to those in technology education. (p. 165)

Ferguson (1993) also recognises this order and disorder in design. This is evident in his description of successful design. He says that:

A successful new design combines formal knowledge and experience and always contains more judgement than certainty. Judgement is brought to bear as the designer responds to the design-in-progress by repeatedly modifying means to reach desired ends. Design is thus a contingent process, subject to changes brought about by conditions that come to the surface after the big decisions have been made. It is also a creative process, in which the designer's imagination is required whenever a contingency occurs. (p. 173)

Creativity then, can be linked to technology education through openended problem solving using design processes for real-life contexts. To solve problems for real-life contexts, designing combines formal knowledge, experience, practice and judgement; both thought and action. The idea of thought and action interaction in technology education is well worth expanding here to clarify the meaning of open-ended problem solving using design processes in this article; that is, going through the entire design process from ideation to the conscious development and testing of the ideas into workable solutions for real-life contexts.

It is worth examining because it is at the root of the demarcation from a prescribed teacher-centred approach to technology education. In reallife contexts, 'action' means moving from modelling found in initial design stages to sorting out ideas, to making prototypes of a selected solution to be tested in the real world; design is creative, dynamic and iterative. In more teacher designated and closed design briefs, the design process is much more linear and 'action' ends with making a model, sometimes even with drawings. Anning, Jenkins and Whitelaw (1996) make the distinction between a model and a prototype. They say:

For designers, a model serves a dual function. It demonstrates to an audience, usually the client, what the image in the mind's eye or from two-dimensional drawings might look like in three-dimensional form. It also clarifies the designer's thinking about the potential and practicalities, as well as the aesthetics, of the proposed 'real' thing (Liddament, 1990). A prototype is something quite different $-\mathrm{a}$ full scale version or pilot of the intended outcome. Teachers are often unclear about these distinctions and consequently may not 
give clear instruction to pupils so that they are confused about the function of models, prototypes, mock ups or a 'real' artefact or outcome. (p. 12)

Technological design processes interpreted as processes of creation and invention for real human needs typically involve a shift from making models to making prototypes. Wiener makes this association when he says, 'in contrast with the more general process of discovery, invention is not complete until it reaches the crafts person. Besides the conditioning of new inventions by the ideas on which they depend, there is a further conditioning in terms of the materials and processes available' (1993, p. 37). This joining of thought and action in making prototypes for real life experiences is critical as a philosophical understanding of technology education where open-ended problem solving and design processes (see Hill, 1994a, 1997) are used to enhance student learning about the technological process. McCormick (1997) writing about conceptual and procedural knowledge, also highlights the importance of skills, knowledge and design process in technology education, the role of each and the importance of relevant context in technological problems.

Jones et al. (1995) examined how young students were taught technology education and found that there was a focus on making models. Jones (1997a) identified problems with this approach:

The 6-8 year old students had difficulty with the idea of a model, often being confused between what is real and what is not. If the students were making the real thing then measurements, materials and equipment were considered to be important. These students could test out their construction and make adaptations. In comparison the students who made models saw little value in making measurements or thinking about appropriate materials. The focus on the model as an end-product meant that students could include compiled components in their design without exploring the appropriateness of the components. Similarly for 11-15 year old students who focused on models as an end-product, the consideration of elements such as materials and cost, were seem in terms of the model. When problems arose the students could dismiss them because a model could include features to overcome those problems. The students modified their designs to take account of the materials available to make models rather than considering appropriate materials for the end-product. The focus on the cardboard model also meant that students' ideas about particular technological concepts were not challenged or learnt during their engagement in the activity. (pp. 90-91)

But can real-life contexts actually translate into school practice in technology education? Some exemplars of technology education that use this approach shed light on the possibilities.

\section{EXEMPLARS OF REAL-LIFE CONTEXTS FOR TECHNOLOGY EDUCATION}

\section{Context}

The two exemplars below report on technology education in Canadian schools in the province of Ontario. Technology education has recently become part of the core curriculum for all children from grades 1 to 9 
(see The Common Curriculum, Ontario Ministry of Education and Training, 1995), after which it becomes an elective in secondary school as Broadbased Technology Programs (see Broad-based Technological Education Programs, Ontario Ministry of Education and Training, 1995). In technology education, regardless of grade level, an open-ended problem solving approach using design processes addresses the technological process of creating, inventing and modifying.

Human factors, societal factors and environmental concerns are crucial to technology education. Together, these three issues make up the three major areas of study - physical products, human processes and environmental systems. According to the Ontario Ministry of Education and Training, all three use technology to adapt the physical and natural world to meet human needs. The technological knowledge and skills that are required for these adaptations are further divided into ten technological concepts - structures, materials, fabrication, mechanisms, power and energy, control, systems, function, aesthetics, and ergonomics (Hill, 1994b, 1994c, 1997).

\section{Methods and data sources}

Case studies (Yin, 1994) were used to document and describe an interpretation of technology education as open-ended problem solving using design processes for real-life contexts. Two exemplars from research are described; one from an elementary school and another from a secondary school.

Data for the elementary school were obtained from teacher and student interviews prior to and during a province-wide technology education celebration event called 'Great Techspectations', May 1993. ${ }^{2}$ Data for the secondary school were obtained from September 1996 to January 1997 through classroom observations, student journals, student design assignments, both student artefacts and portfolios, student and teacher interviews, student and teacher journals and student displays. ${ }^{3}$

\section{Exemplar 1: An elementary school ${ }^{2}$}

In 1992, the concept of technology education as part of the core curriculum in Ontario elementary schools was at its inception. A few pioneering technology education consultants at the school board level were working with some enthusiastic elementary school teachers. The consultants not only gave workshops about technology to provide technological skills and knowledge, and problem solving processes, but they worked with teachers and students in classrooms. These endeavours led to innovative teachers implementing technology education in their classes prior to 1995 when the curriculum document was released.

To study technology, the teacher and students in one grade 1 class (5-7 year olds) in an elementary school in northeast Ontario decided to write and produce a play. First they agreed on the topic of the play. A consensus building process was used by the teacher to decide on the topic of the 
play. Student and teacher suggestions were discussed and the teacher guided students through the sorting out of ideas and the decision making. This process permitted students to bring their world, their ideas into the activity. In primary grades, real-life contexts are mainly the children's personal world; their home, family, school and classroom environments. As they progress from primary to junior grades life contexts beyond these environments take on more prominence.

The class then wrote the play and used computers to produce the script. Decisions were made about how the play was to be produced; for example, decisions about actors/actresses, set and props. Once initial decisions had been made, students prepared their actresses and actors to act out the play; two soft, stuffed fabric dolls, a Raggedy Ann and a Raggedy Dan.

To do this, plastic tubing and syringes filled with water were attached to the dolls with tape. The teacher taught concepts of pneumatics and hydraulics, and how to design systems to enable them to proceed with the task. Once the hydraulic systems were fixed to the dolls, students practised using the syringes to control the dolls' movements. They also constructed the set and props using cardboard and other supplies and materials, new and recycled. Students rehearsed the play until they were confident with the production. Then the show opened.

Throughout the activities, students were involved in a variety of technological problem solving activities; for example, some worked on the set, some with the actresses and actors - creating movement in the dolls with the use of the hydraulic systems, and some videotaped the production. The entire class was involved in the various activities and many school subjects were used in the theme of writing, producing and videotaping the play.

The students brought their world, their real-life, into the classroom by deciding on the topic and content of their play, and by using their toys from home. They also selected the technological concepts they would use for the activities from a variety of possibilities established by both students and the teacher, for example hydraulics to create movement in the dolls. The theme and activities provided many opportunities for students to solve technological problems using the design process. Creativity was fostered by allowing students to find original solutions to their problems. Students displayed various types of creativity, such as productive creativity with the hydraulic system design for their dolls' movement, inventive creativity with the use of their dolls and the set and props design, and emergentive creativity through, at least, the writing of the play.

Through student and teacher questions, students thought about the effect of the technology on their lives and on how they produced the play. How would such a play have been produced with technology other than hydraulics and pneumatics? How would students have recorded their play before the invention of the video camera? What was life like before such inventions? And how have such inventions affected life today? Issues of the environment were brought into classroom talk by using as many recycled materials 
as possible for the set and props. How did their use of recycled materials help the environment?

These types of activities, decisions and discussions indicate that young students were able to successfully complete technological problems, talk about the technological concepts that they had learned and were quite capable of discussing issues about technology that affect their world. The key was the type of problems and issues that were addressed. They were from the children's world and their class environment allowed the problems and issues to be framed in their language. The young children were capable of thinking about and operating in real-life contexts for technology. As Jones (1997a) found, they often find this easier than to operate in situations of abstract projects assigned by the teacher.

While problem solving using design processes, children learn technological concepts and skills (knowledge and understanding). Situating these activities in real-life contexts not only enhances this learning, but also fosters children's thinking about human and environmental consequences of their design. This approach to technology education is not unique to Ontario, Canada. Other countries, for example New Zealand, are implementing real-life technological problem solving contexts in technology education (Alister Jones, Waikato University, has produced a series of video tapes titled 'Know How 2' that provide school examples in New Zealand).

The inclusion of technology education in elementary school curriculum has additional advantages beyond learning about technology. Children learn naturally by playing and making. With an emphasis on the creative process and real-life technological problem solving using design processes, technology education is a natural forum for young children's learning. It also provides an opportunity to celebrate a variety of intelligences (see Gardner, 1983, 1993) and learning styles, recognising that students also discover and learn with their hands and not just with books. The question of how technology education enhances children's learning is an important area for future research.

\section{Exemplar 2: A secondary school ${ }^{3}$}

In a secondary school in southeastern Ontario, projects in grade 10 and 11 Manufacturing Technology courses were based on community needs whenever possible. The teacher was well-known in the local school community for a community project-based approach to learning in his technology courses. He had also won a Prime Minister's Award for Teaching Excellence in Science, Technology and Mathematics.

The teacher and students brought community project ideas to class and complied a list of possible projects. The teacher received ongoing requests for partnerships with his classes through community sponsored projects. All community project suggestions were scrutinized by both the teacher and the school principal to ensure that students would be the beneficiaries of the project; that is, the project would meet required course content, provide 
an enriching real-life design experience for students, and the community partner would provide resources, both financial and human, to enable successful student completion of the project. Once the project was approved it was added to the project list. Community members were advised that their suggested project was added to the list, but since students chose their project of interest, there was no guarantee that it would be made. If selected, students, the teacher and the community partner would work together as a team. There were other types of negotiation in class; students negotiated their project selection with the teacher. The first few weeks of the course were designated to sorting out student groups and their project(s).

One grade 11 female student decided to work with a retirement home as her community partner. Prior to the commencement of the course, the teacher had met with staff and administrative members of the retirement home. Needs were identified and an initial list of technological problems was created. Once the course began and this problem was selected, the teacher and the student met with the community partner to discuss and prioritise identified needs, and to consider the student's interests and the project constraints due to available class time. Two items from the retirements home's list of technological problems were chosen by the student as course projects.

One need of the retirement home was the modification of a laundry bin used by staff to move wet clothes from the washing machines to the dryers, and dry clothes from the dryers to tables where the clothes were folded. The removal to heavy, wet laundry from the deep bins had resulted in back injuries of several employees, and in workers' compensation applications. Even with injury occurrences and complaints from employees, no action was taken by the employer to improve or replace the laundry bins. However, when all staff had to stay home for a week due to cases of employees with 'flu and administration's fear that it might spread to the residents, the administration was obliged to do the laundry; the staff work. Once administrators used the laundry bins, the problem became clear to them. The problem of the laundry bins became recognised as a problem that needed to be solved and was offered as a project to the school.

The second need of the retirement home arose from the desire of residents, now in wheelchairs, to garden during the summer months. Some kind of a gardening table was required. The student decided to work on both projects simultaneously during the semester. The gardening table project is described in detail here and represents a real-life context for technological problem solving in a secondary school, with many iterations of design along the way.

The project began with a meeting in the courtyard of the residence where the table was to be placed. The student, the teacher and residence administrators and staff discussed design constraints and specifications. These initially had been obtained by the teacher from the retirement home employees who had consulted with the residents. In preparation for this community partner meeting, the student had drawn many thumbnail sketches 
from initial information gleaned from the teacher and other sources. These drawings were presented at the meeting.

Several of the sketches were selected as potential projects and each design idea was discussed. By the end of the meeting, one design had been selected for further development. It was a gardening table made of a steel frame and poured concrete. This design was chosen after the community partner, the student and the teacher compared the initial problem constraints and specifications to each design. The student then returned to class to generate more detailed design ideas for a gardening table made of steel and concrete.

In an interview, when asked to describe the method used to communicate initial project ideas, the student said, 'It was hard to tell other people about it, 'cause they didn't know what I meant when I said I was making a gardening table. So I had a lot of drawings. I have a lot of drawings now that I didn't use because we are not using that kind of a design. But that's what I used when I showed people what I was doing . . . A lot of them were rough sketches (Student interview, 1995.11.20). The student continued describing her experience about ideation for the selected design and the translation of rough sketches to computer drawings:

When I thought that I had a design that I thought they [the residents, would really like and I wanted them to be able to understand what I meant, the design would be translated from a rough sketch to a computer [sketch]. It got to the point that we thought we could start building the steel frames for the concrete tables. That's when I did the computer designs, to be able to decide how much steel we needed and how much concrete. So I took a good computer drawing to them.

As the student reworked her design ideas and sketches, she made a small scale model out of wood. This design refinement was done with the student spending her time in a wheelchair that was borrowed from the retirement home in order for her to get a better understanding of life in a wheelchair. Dreyfus' Human Scale Dimension charts were used to obtain measurement specifications.

At this stage, another meeting with the community partner took place. This meeting led to a revision of the design; away from the idea of a steel frame and concrete to fibreglass. The student described her frustration with the process at this point:

And then I found out that they didn't want that at all. I can't remember what the reason was for not wanting the design. It was kind of disappointing because I had at least 20 drawings for them. And then they didn't want the design. (Student interview, 1995.11.20)

But upon refection she realized that reasons were clear, and that her disappointment had momentarily prevailed after the meeting:

And it was kind of good in a way because then we didn't have to work with steel frames, which was going to be difficult to cut and to weld. And the fibreglass seemed like a better idea to me because it's not going to need to be painted and need a lot of time to make it smooth so it doesn't tear your [the residents'] skin. I think it will be better for the residents to have it in fibreglass. It's going to be easier to work with anyway. It won't be as heavy. (Student interview, 1995.11.20) 
In interviews with the teacher, he talked about a pattern of high and low periods in technological problem solving. He communicated to students that this was a normal part of the process in real-life contexts.

So the design continued to evolve, from a steel frame and concrete structure to a fibreglass construction. The student's limited knowledge about welding, time limitations due to the length of the course, and the community partner's input about the weight and coarse surface texture of concrete were key factors that influenced the design changes. The smooth surface of fibreglass was deemed safer for the fragile skin of the residents.

The student continued to develop design ideas for the fibreglass gardening table but simultaneously continued her investigation of other possible materials. She still saw the design as evolving as she had some concerns about the fibreglass. Her research on the fibreglass idea had revealed that fibreglass would be too expensive and would take too long to make in the remaining class time. The process of layering and curing fibreglass would be time consuming and a substantial amount of time would be needed to learn new skills in order to use the material. Further research into materials led to the investigation of plastic wood. The student decided that the plastic wood would be an appropriate material to use as it was affordable, its surface texture was smooth and would not tear the residents' skin, it would need minimum maintenance as plastic wood does not deteriorate, it was made of recycled plastic thereby responding to environmental concerns, it would allow for the project to be completed within the remaining course time, and the skills required to use this material could also be learned in the class environment. The investigation of materials and the design change is a perfect example of how Wiener (1993) sees design as an innovative and explorative process: 'Besides the conditioning of new ideas .... there is a further conditioning in terms of the materials and processes available' (p. 37).

The change in material led to a change in the design of the gardening table's top, which in turn lead to a change in the leg design to accommodate the new top design. Another visit to the residence with new drawings led to the final selection of the design and materials. In reflecting on the preconstruction process, the student offered some constructive suggestions. She said that 'more meetings [with the residents] would have shortened the design [idea stage of the design process]. And if I had done computer sketches and a model as soon as I had the first idea then they could have said right at the beginning . . . that they wanted something different' (Student interview, 1995.11.20). The student was reflecting on the fact that she had only thumbnail sketches during initial meetings. Communication would have been enhanced if more detailed drawings and 3-dimensional models were used to communicate her ideas.

Next the student planned for the design's construction and began to build the project. Due to the fairly long process for the selection of a design solution, class time was running out and the student needed help from other students to construct the gardening table. Another design team, a group 
of four that was further ahead in their project, assisted in the construction of the gardening table. At various times in project construction, students cleaned the classroom and displayed their unfinished projects. This created a great sense of pride and a source of motivation. Once the gardening table was finished, the student used her weekly journal entries that documented her exploration using the design process to compile a final clean design report. There was also a celebration at the retirement home when all students who had worked on the gardening table presented it to the retirement home.

But it not just a matter of a project and activity-based learning that are important in this alternative approach to technology education. The context, need for the project and related technological activities are critical. Dewey talks of this in his dialogue of experience. He says that 'it is not enough to insist upon the necessity of experience, nor even of activity in experience. Everything depends upon the quality of the experience'. He describes two aspects of quality. 'There is an immediate aspect of agreeable or disagreeableness, and there is its influence upon later experience' (1977, p. 27). Miller (1985), in discussing the pragmatic classroom says, 'learning is achieved by relating activity to past experiences, current interests, and practical applications of the here and now' (p. 201).

Layton (1993) places importance on the role of context in cognitive activities in science education and says, 'The syncretic knowledge that is constructed in everyday practical action has similarities to technological knowledge' (p. 71). Jenkins (1993) points out the challenge that research on context brings to education. He points out that, 'Technology education promises a particularly interesting response to this challenge, since it presupposes that heuristics are not absolute and offers an opportunity both to revalue tacit knowledge within education and to re-affirm the usefulness of such knowledge in solving problems' (p. 86). McCormick et al. (1996a, 1996b) incorporate situated cognition literature in the theoretical basis of their research. 'This perspective draws attention to the importance of the relationship of knowing and doing, and to the process of enculturation, where the learner is increasingly participating in authentic activities. . . Thus learning technology is to learn to participate in the communities of practice of technologists' (p. 4).

In interviews, two students in the grade 10 Manufacturing Technology class talked about what it means to learn through community based projects. Their dialogue confirms recent research findings on active learning in context:

Community projects give you good experience in all different types of things, school subjects and life [applications of knowledge]. It doesn't just lead to one thing you are going to do [occupation], it gives you variety of everything [life experiences]. (Bob Group interview, SC, 1995.12.05)

It gives you like, you know how school is. School, and then you want to grow up, and leave, do other stuff that has nothing to do with school. Both together, you don't feel like you are doing it [the learning], for no reason, like most schooling is. (Bob Group interview, SA, 1995.12.05) 
Two grade 11 students in the Manufacturing Technology class examined earlier, talked about involving community needs in school projects. They reveal social concerns and connect this type of school experience to life after high school:

I think it's a big part of the projects. If we didn't do it, then a lot of things wouldn't get done. They [community members] would have to pay for professional contractors. For things like the retirement home, its good for the old people. (GY Group interview, HI, 1995.11.17)

It's profitable for both people. They [the community] get something that they can use, that they need, and we [the students] get the experience of building it, of working on it for an entire semester. (GY Group interview, JE, 1995.11.17)

It's good for whatever you go into later. It's such a challenge. I don't know, I found it a challenge. (GY Group interview, AL, 1995.11.17)

Now how do we begin to prepare future teachers for this kind of practice? Practice that brings real life contexts into the classroom? Practice that requires of students to be involved in their own learning and actively engaged in real-life projects where theory is learned and confirmed through practice? Hill (1997) provides exemplars of real-life technological projects in teacher education where pre-service teachers, in their teacher education program, model what they will expect of their secondary school students. Hill and Hopkins (1997) present a collaborative model for teacher education where school practice and teacher education practice work together toward implementing real-life contexts for technology education, and preparing future teachers for this practice.

\section{EDUCATIONAL IMPLICATIONS OF PROBLEM SOLVING IN REAL-LIFE CONTEXTS FOR TECHNOLOGY EDUCATION}

Technological problem solving, when set in the context of authentic world problems, and real human needs invokes exciting possibilities for technology education. Here, technological problem solving using design processes moves from making models, to making prototypes for real-life contexts.

These possibilities have been at the heart of this paper.

1. In this interpretation of technology education, we move from a systematic, linear interpretation of design processes to an interpretation of design processes as iterative and as guides for exploration that encourage confidence to explore and to take risks.

2. The confidence to explore, discover and take risks becomes critical when we understand that in creation and invention, there are always states of order and disorder.

3. Discovering that order with disorder involves cognition and application, knowledge and control, mind and matter, purpose and tools will be of increasing importance to those in technology education (Waetjen, 1995, p. 165). 
4. The interaction between thought (bodies of knowledge and structures) and conceptual knowledge, and action (activities and the act of structuring) and procedural knowledge is key to understanding how children learn technology.

5. This approach sees the technological process as creation, invention and modification, and builds on knowledge making, not knowledge receiving.

6. The real-life contexts move design processes from model making as the end result, to the completion of prototypes.

7. This approach is supported by research on situated cognition (Lave, 1988, 1991).

8. Looking at technology as formalised practice links technology directly to culture, because culture is a set of socially accepted practices and values (Franklin, 1993, p. 15).

9. Technological problem solving in and for real-life contexts is critical to a philosophical understanding of this alternative approach to technology education, and guides teacher and student practice.

\section{CONCLUSION}

This paper examined an alternative approach to technology education that is a demarcation from what is typically found in schools; design, make and appraise cycles based on closed design briefs that are teacher assigned and unrelated to the students' world. Design process is frequently depicted as prescribed, systematic and linear.

An alternative approach is to interpret technology education as problem solving in real-life contexts using design processes as tools for creation and exploration. To be 'authentic', technology education needs to relate to real-life problems, or contexts. In order to do this, the way the design process operates must be understood and at the heart of the educational practice in technology education. The design process is not a neat systematic process. Instead it has iterative patterns, has to produce some order from disorder and shares features of what has been explored in research on creativity. A further key concept in technology education is the need to combine thought with action-conceptual and procedural knowledge.

Researchers using this alternative approach to technology education need to write about and disseminate their work to provide a better understanding of the complexity of real-life design and the advantages of teaching technology education through this design lens.

\section{ACKNOWLEDGEMENTS}

I am grateful to Alister Jones, The University of Waikato, and to Angela Anning, The University of Leeds, for their comments on an earlier draft of this manuscript. 
NOTES

1. An early version of this paper, 'Designing and Making: Open Possibilities for Technology Education', was presented at the Annual Meeting of the American Educational Research Association, April 8-12, 1996.

2. Much of this work began with a grant from the Eastern Ontario Technological Education Council (EOTEC) and sponsorship from the Ontario Ministry of Education and Training, to chair and organise the Children, Design and Technology: K-6 Symposium in May 1993 at Queen's University; the first such symposium in Ontario.

3. The data from secondary school Manufacturing Technology classes are from research conducted by A. M. Hill and H. A. Smith, Queen's University, and supported by a Strategic Grant No. 812-95-004 from the Social Science and Humanities Research Council of Canada, under the theme Science Culture in Canada.

\section{REFERENCES}

Anning, A., Jenkins, E. \& Whitelaw, S.: 1996, Bodies of Knowledge and Design-based Activities: A Report to the Design Council, The University of Leeds, Leeds.

Beakley, G. C.: 1975, Introduction to Engineering Graphics, MacMillan, New York.

Cross, N.: 1983, Design: Processes and Products Course Units, Open University Press, Buckingham.

Dewey, J.: 1977, Experience and Education (20th printing), MacMillan Collier, New York. Dunn, S. \& Larson, R.: 1990, Design Technology: Children's Engineering, The Falmer Press, Lewes.

Eggleston, J.: 1992, Teaching Design and Technology, Open University Press, Buckingham. Ferguson, E. S.: 1993, Engineering and the Mind's Eye, The MIT Press, Cambridge.

Franklin, U.: 1990, The Real World of Technology, Anansi Press, Toronto, ON.

Friesen, D.: 1997, 'Exploring Self-Study from a Postmodern Perspective'. Paper presented to the Annual Meeting of the American Educational Research Association, 24-25 March, Chicago, IL.

Gardner, H.: 1983, The Theory of Multiple Intelligences, Basic Books, New York.

Gardner, H.: 1993, Multiple Intelligences: The Theory in Practice, Basic Books, New York.

Hill, A. M.: 1994a, 'Perspectives on Philosophical Shifts in Vocational Education: From Realism to Pragmatism and Reconstructionism', Journal of Vocational and Technical Education 10(2), 37-45.

Hill, A. M.: 1994b, 'Technology in the Elementary School', MSTE News 4(1), 1-4.

Hill, A. M.: 1994c, 'Technology in the Elementary School', Technology Teacher 55(5), 19-23.

Hill, A.M.: 1997, 'Reconstructionism in Technology Education', International Journal of Technology and Design Education 7(1-2), 121-139.

Hill, A. M. \& Hopkins, R.: 1997, 'Two Paths Converge: A Story of University and School Collaboration in Teacher Education'. Paper presented to the International Study Association on Teacher and Teacher Thinking (ISATT), 8th Annual Conference, 1-5 October, Kiel, Germany.

Hill, A. M. \& Smith, H. A.: 1996, 'The Evolution of an Exemplary Secondary School Program in Technological Education: An Ontario Perspective'. Paper presented to the 8th Symposium of the International Organization of Science and Technology Education (IOSTE), 17-24 August, Edmonton, AB.

Hill, A. M. \& Smith, H. A.: 1997, 'Bringing Classroom Design and Community-based Projects Together: Attributes of an Innovative Technology Education Program'. Paper presented to the Annual Meeting of the American Educational Research Association, 24-25 March, Chicago, IL.

Jenkins, E.: 1993, 'Knowledge and Action: Science as Technology?', in R. McCormick, P. 
Murphy \& M. Harrison (eds.), Teaching and Learning Technology, Addison-Wesley for The Open University Press, Wokingham, pp. 3-14.

Jones, A.: 1997, 'Recent Research In Learning Technological Concepts and Processes', International Journal of Technology and Design Education 7(1-2), 83-96.

Jones, A.: 1997, Know How 2, Video Modules, Copeland Wilson, Wellington.

Jones, A. \& Carr, A.: 1994, 'Students Technological Capability: Where Do We Start?', SAMEpapers 1994, 165-186.

Jones, A., Mather, V. \& Carr, A.: 1995, Issues in the Practice of Technology Education, Centre for Science and Mathematics Education Research, University of Waikato, Hamilton.

Kimbell, R.: 1986, Craft Design \& Technology, The Open University Press, Milton Keynes.

Lave, J.: 1988, Cognition in Practice: Mind, Mathematics and Culture in Everyday Life, Cambridge University Press, Cambridge.

Lave, J.: 1991, 'Situated Learning in Communities of Practice', in L. B. Resnick, J. M. Levine \& S. D. Teasley (eds.), Shared Cognition: Thinking as Social Practice, Perspectives on Socially Shared Cognition, American Psychological Association, Washington, DC.

Lawson, B.: 1990, How Designers Think, Butterworth Architecture, London.

Layton, D.: 1993, 'Science Education as Praxis', in R. McCormick, P. Murphy \& M. Harrison (eds.), Teaching and Learning Technology, Addison-Wesley for The Open University Press, Wokingham, pp. 3-14.

McCormick, R.: 1997, 'Conceptual and Procedural Knowledge', International Journal of Technology and Design Education 7(1-2), 141-159.

McCormick, R., Murphy, P. \& Hennessy, S.: 1994, 'Problem Solving Processes in Technology Education: A Pilot Study', International Journal of Technology and Design Education 4(1), 5-34.

McCormick, R., Murphy, P., Hennessy, S. \& Davidson, M.: 1996a, 'Research on Student Learning of Designing and Problem Solving in Technology Activity in Schools in England'. Paper presented to the Annual Meeting of the American Educational Research Association, 8-12 April, New York.

McCormick, R., Murphy, P., Hennessy, S. \& Davidson, M.: 1996b, 'Problem Solving in Science and Technology'. Paper presented to the Annual Meeting of the American Educational Research Association, 8-12 April, New York.

Milgram, R. A.: 1990, 'Creativity: An Idea Whose Time Has Come and Gone?', in M. Runco \& R. Albert (eds.), Theories of Creativity, Sage Publications, London, pp. 215-233.

Miller, M.D.: 1985, Principles and Philosophy for Vocational Education, The Ohio State University, The National Center for Research in Vocational Education, Columbus, $\mathrm{OH}$.

Norman, E., Riley, J., Urry, S. \& Whittaker, M.: 1990, Advanced Design and Technology, Longman, Essex.

Ontario Ministry of Education and Training: 1995, The Common Curriculum, Queen's Printer, Toronto, ON.

Ontario Ministry of Education and Training: 1995, Broad-based Technological Education, Queen's Printer, Toronto, ON.

Raizen S. A., Sellwood, P. Todd, R. D. \& Vickers, M.: 1995, Technology Education in the Classroom: Understanding the Designed World, Jossey Bass Publishers, San Francisco.

Runco, M. \& Albert, R.: 1990, Theories of Creativity, Sage Publications, London.

Taylor, C.: 1991, 'The Dialogical Self', in D. R. Hiley, J. F. Bohman \& R. Shusterman (eds.), The Interpretive Turn: Philosophy, Science, Culture, Cornell University Press, Ithaca, pp. 304-314.

Taylor, I.: 1975, 'An Emerging View of Creative Actions', in I. Taylor \& J. V. Getzels (eds.), Perspectives in Creativity, Aldine, Chicago, pp. 297-325.

Tickle, L.: 1990, Design and Technology in Primary School Classrooms: Developing Teachers' Perspectives and Practices, The Falmer Press, Lewes.

Waetjen, W. B.: 1995, 'Technology and the Humanities', in G. E. Martin (ed.), Foundations of Technology Education, 44th Yearbook, Council of Technology Teacher Education, Glencoe/McGraw/Hill, Peoria, IL. 
Walker, D. \& Cross, N.: 1983, An Introduction to Design, Open University Press, Buckingham. Wallas, G.: 1926, The Art of Thought, Harcourt, Brace and Co., New York.

Wallas, G.: 1973, 'The Art of Thought', in P. E. Vernon (ed.), Creativity: Selected Readings, Penguin, Harmondsworth, pp. 91-97.

Wiener, N.: 1993, Invention: The Care and Feeding of Ideas, The MIT Press, Cambridge. Williams, P. H. M.: 1990, Teaching Craft, Design and Technology: Five to Thirteen, Routledge, London.

Yin, R. K.: 1994, Case Study Research: Design and Methods (2nd ed.), Sage, Thousand Oaks. 